\title{
CLINICAL FEATURES AND OUTCOME OF KAWASAKI DISEASE IN CENTRAL TUNISIA: A MULTICENTER STUDY ABOUT 65 CASES
}

H. Ajmi ${ }^{1}$, S. Ghorbel ${ }^{1}$, C. Jamila ${ }^{1}$, N. Kahloul ${ }^{2}$, K. Helal ${ }^{3}$, F. Majdoub ${ }^{1}$, S. Mabrouk ${ }^{1}$, J. Chemli ${ }^{1}$, N. Zouari ${ }^{1}$, L. Boughammoura ${ }^{2}$, S. Hassayoun ${ }^{1}$, S. Abroug ${ }^{1}$

${ }^{1}$ Pediatric department, Sahloul University Hospital, Sousse, Tunisia.

2Pediatric department, Farhat Hached University Hospital, Sousse, Tunisia.

${ }^{3}$ Pediatric department, Ibn El Jazzar University Hospital, Kairouan, Tunisia

\section{BACKGROUND AND AIMS}

The epidemiological and clinical features of the Kawasaki disease differ widely among ethnic groups and seem to be higher in the Asian populations. In Tunisia, no recent data are available.

the aim of this study is to analyze the clinical features and course of Kawasaki disease in central Tunisia

Method:

We studied retrospectively sixty-five cases of children with Kawasaki disease collected in Tunisian center pediatric departments during 17 years (2000- 2017).

\section{RESULTS}

43 boys and 22 girls (sex - ratio=1.95)

* Age between 2 months and 10 years old (mean age= 2.5 years old).

* Parental consanguinity was found in $20 \%$ of cases.

* The fever was found in all cases. The temperature value averaged was of $39.0\left(38\right.$ to $\left.40.5^{\circ} \mathrm{C}\right)$

* The duration of the fever at the time of hospitalization was on average 9.8 days with extremes ranging from 2 to 32 days.

Fifty-eight patients had at least 5 diagnostic criteria of the illness

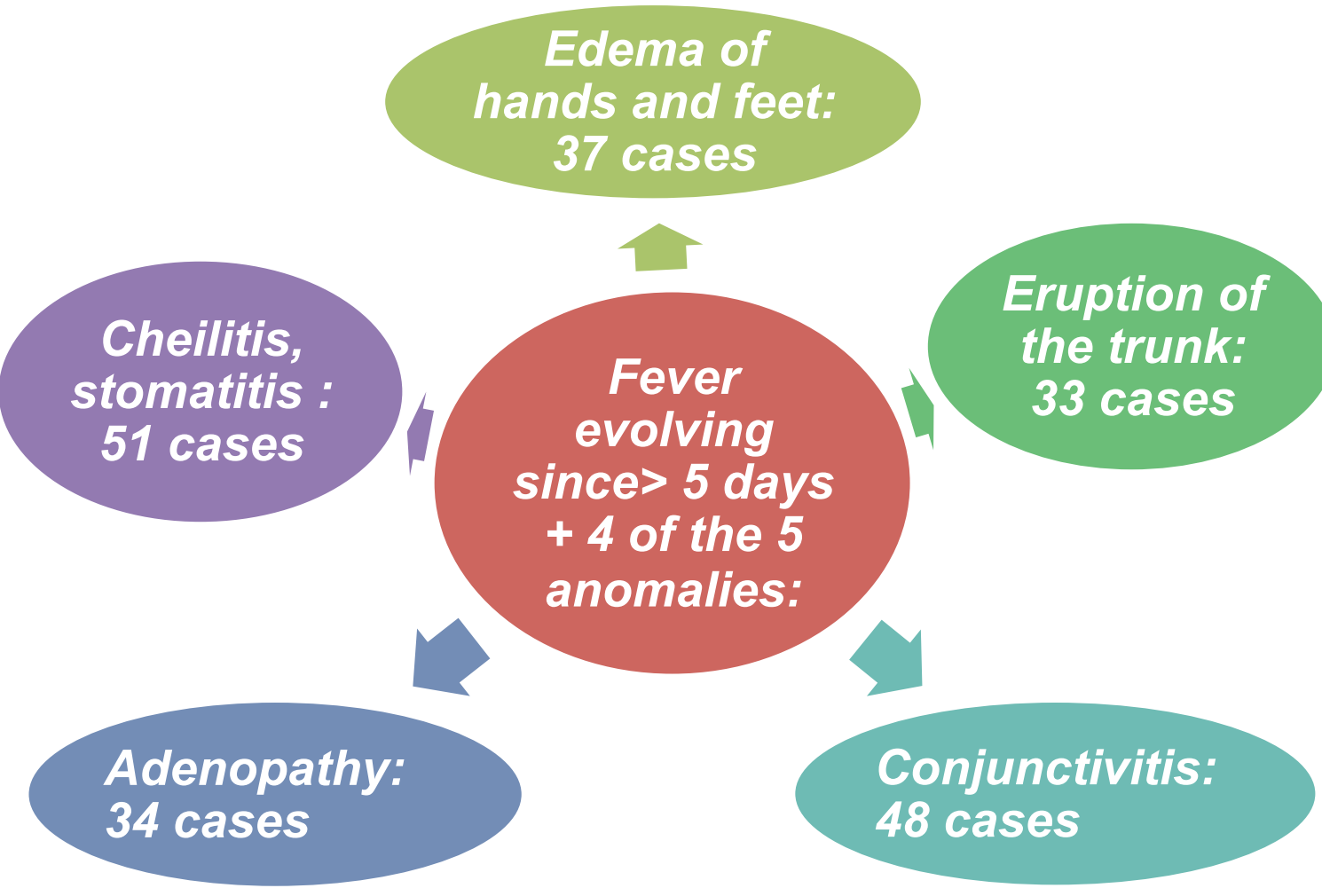

Figure 1: clinical features of patients with Kawasaki disease

* An infectious episode prior to hospitalization was noted in $32.3 \%$ of cases Positive CMV serology was found in three cases.

Table I: Biological data of patients with Kawasaki disease

\begin{tabular}{|l|c|c|}
\hline & Number of case & $\%$ \\
\hline Anemia & 33 & 50,8 \\
\hline $\begin{array}{l}\text { Thrombocytosi } \\
\text { s }\end{array}$ & 27 & 41,5 \\
\hline High ES (>20) & 50 & 76,9 \\
\hline $\begin{array}{l}\text { High CRP } \\
\text { (>50mg/l) }\end{array}$ & 47 & 72,3 \\
\hline Cytolysis & 20 & 30,8 \\
\hline
\end{tabular}

* Cardiac ultrasound was done in all cases.

cardiac complications in 24 Patients: it was a coronary aneurysm in 8 cases, dilated coronary in 23 cases,
* pericarditis in one case and arhythmia in two cases.

The normalization time of the echocardiogram was on average 28.7 days with extremes ranging from 2 to 48 days.

\section{Table II: Echocardiography data}

\begin{tabular}{|ll|}
\hline Cardiac ultasound results & Numbre of cases \\
\hline Normal & 45 \\
\hline Coronary aneurysm +dilated coronary & 6 \\
\hline Coronary aneurysm & 2 \\
\hline Dilated coronary withoun aneurysm & 13 \\
\hline Two coronary dilated & 3 \\
\hline One coronary dilated & 21 \\
\hline Aneurysm of two coronary & 1 \\
\hline
\end{tabular}

- Initial treatment : Intravenous immune globulin in 55 patients.

Table III: treatment of patients with Kawasaki disease

\begin{tabular}{|ll|}
\hline Treatment & $\begin{array}{l}\text { Number } \\
\text { of case }\end{array}$ \\
\hline Intravenous immunoglobulin & 55 \\
\hline Aspégic $(80 \mathrm{mg} / \mathrm{kg} / \mathrm{j})$ & 63
\end{tabular}

* The evolution : 7 patients did not respond to the initial treatment, and required corticosteroids. Then the evolution was favorable for 64 Patients.

* In one case coronary lesions were severe characterized by the occurrence of myocardial infarction with left ventricular dysfunction.

\section{CONCLUSION:}

Kawasaki disease is not rare in Tunisia. Incomplete or atypical presentations are the most source of diagnostic delay and coronary aneurysm is still the most dangerous complication observed in patients with Kawasaki disease. 